\title{
Practice-Based Learning as Lever for Successfully Adapting Supply Chain 4.0 Technology: Foreground People
}

\author{
Henning de HAAS ${ }^{1}$ and John Bang MATHIASEN \\ Aarhus University, Department of Business Development and Technology
}

\begin{abstract}
SCM 4.0 is expected to lead to increased automation and transparency throughout the supply chain; thus, opportunities for operational efficiency and digital enabled business models [1], [2]. However, the SCM 4.0 impacts the decision-making towards higher complexity [3]. Technology-wise many companies have adapted SCM 4.0. This paper claims that organizational and leadership matters have not yet gone through similar transition; Actually, we can neither see any changes in the way companies organize supply chains nor in how they facilitate practice-based learning of employees and leaders. With SCM 4.0 technologies, an effective supply chain is not just a question of transforming components to finished goods. Rather, the contemporary SCM organizations need a strong transdisciplinary practice-based learning agenda to be able to deliver customer value [4], [5]. With the purpose of understanding transdisciplinary levers for practice-based learning in SCM, the study builds on two cases of implementation of SCM 4.0 technologies, exploring how the case companies have managed the transformation from a classic 2.0 to a 4.0 practice-based learning organization. The research question guiding the study is: to what extent can practise-based learning be a lever for adapting SCM 4.0?
\end{abstract}

Keywords: SCM 4.0, learning supply chain, practise-based learning

\section{Introduction}

Industry-wide, supply chain management faces the challenges from new digital technologies known as Supply Chain 4.0 (SCM 4.0) [6], [7]. The transformation to SCM 4.0 is expected to lead to increased automation and transparency throughout the supply chain; thus, opportunities for operational efficiency and digital enabled business models [1], [2]. The new technologies (SCM 4.0) impacts the decision-making towards higher complexity [3]. This paper claims that organizational and leadership matters have not yet gone through similar transition; Actually, we can neither see any changes in the way companies organize supply chains nor in how they facilitate practice-based learning of employees and leaders.

Supply Chain 4.0 sets the agenda for a digitised transformation of Supply Chain Management (SCM). Digitalization of SCM, entailing integration and transparency of data and information enables new opportunities for operational efficiencies, sustainability and new business models. [8], [6]. SCM 4.0 builds on the fourth industrial revolution - also named as Industry 4.0. [7]. The scope is the integration of the factory with the entire product lifecycle and supply chain activities. This is predicted to change the way people work. [7], [1], [6]. Digitalisation of supply chain can be seen as "a radical

\footnotetext{
${ }^{1}$ Corresponding Author, Mail: hdh@btech.au.dk.
} 
change in products and services, processes, or entire business models through the application of digital technology" [6].

The transition from SCM 2.0 to SCM 4.0 seems to be fuelled by the development of new digital tools for integration in information flow and decision support, as well as automation of processes. The transition escalates both the pace of changes and in particular the complexity of the decision making in the supply chain [7], [1], [6], [2]. With SCM 4.0 technologies, more data will be available for decision making. However, data needs context and reflection to become knowledge. Effective supply chain management is not just a question of transforming components to finished goods. Rather, the contemporary SCM organizations need a strong transdisciplinary practice-based learning agenda to be able to deliver customer value [4], [5].

In the beginning of year 2000, the supply chain complexity was the effect of globalization, e.g. having manufacturing placed in overseas areas (Asia) and markets in Europe, USA, etc. In 2020 the complexity in supply chain is still coming from the dispersed supply chain structure. However, also from the quest for digitalization. The increased volume of data to be handled, increased number of relations to be managed, is making prediction of what is going to happen e.g. forecasting demand, a difficult task. This increased complexity can lead organizations and people to a "lock-in" where there is no decisions and no actions, as we drive our supply chains based on the year 2000 habits, in a business and organisational context that is much more complex. To solve this leadership dilemma there is a need to develop a learning organization that can adapt to the new complexity from SCM 4.0. With the purpose of understanding transdisciplinary levers for practice-based learning in SCM, the study builds on two cases of implementation of SCM 4.0 technologies, exploring how the case companies transform from SCM 2.0 to SCM 4.0 using practice-based learning as a lever.

The research question guiding the study is: to what extent can practise-based learning be a lever for adapting SCM 4.0?.

\section{SCM 4.0 and Learning}

To understand the complexity in organisation and leadership in the SCM4.0 era this section will explore SCM, SCM4.0 and digitalization as well as practise-based learning.

The notion of a supply chain has been known for nearly 40 years [9]. Most definitions seem to revolve around three elements 1) the network structure, 2) the business processes and 3) management components. This definition has been widely used "A network of connected and interdependent organizations mutually and cooperatively working together to control, manage and improve the flow of materials and information from suppliers to end users" $[10$, p. 19]. A similar definition [11] of SCM states that it is about integration of key business processes from end user through original suppliers that provides products, services, and information that add value for customers, and other stakeholders. SCM includes both up- and downstream activities respectively focused on supply and manufacturing and logistics and distribution. Most models used to describe a supply chain is highly structural. The scope of the models is the material flow, how to balance inventories, cost optimize the supply chain, re-engineer the business processes etc. [11], [12], it is very rare to find people, learning and leadership in the supply chain models and concepts.

A successful supply chain depends on the integration of the value chain entities in order to create a collaboration that facilitates the exchange of information, materials and 
cash flows [13]. Both in practice and in academia, the main focus is optimization of the flow of information and material, sourcing channels and planning concepts of various kinds to deliver good customer service.

Industry 4.0 or SCM 4.0 is the latest development stage in the industrial development. The first industrial revolution (Industry 1.0) was in the end of the $18^{\text {th }}$ century when manufacturing was powered by steam engines. The second industrial revolution in the start of the $20^{\text {th }}$ century, I2.0 - was when electricity could be used to power machines in production [7], [1], [2]. This gave a high flexibility of manufacturing e.g. regarding layout. The third industrial revolution was in the 70ies by the introduction of the computer and first cases of automation. This led to the current concept of Industry 4.0. The drivers behind I4.0 can be seen as a demand pull, i.e. customers requesting fast service, short delivery time, more individualized products etc. and a technology push through new opportunities for automation of manufacturing processes and administrative processes, information integration across the supply chain creating transparency. SCM 4.0 can be defined as "A supply chain which involves close collaboration of different stakeholders (e.g. suppliers and customers) and is built on digital technology, including but not limited to, web-enabled technology, cloud computing and Internet of Things" [8], [14].

The global logistics company DHL is on a yearly basis updating a "Logistics trend Radar" [15] where a map is created of the state of development, in technologies and social/business trends against their likelihood to make disruptive impact on logistics (supply chain) and against an impact timeline of under/over 5 years. Examples of technologies are IoT-Internet of Things that is expected to have an impact on logistics in less than 5 years and have the potential to connect anything to the internet and accelerate the data-driven logistics. In the other end of the scale we have Self-driving vehicles. This is expected to have impact in more than 5 years. On social and business trends we find examples of a trend that is expected to have high disruptive impact in 5+ years is named as "supergrid logistics" [15]. This is described as going beyond 4PL logistics and raise a new generation of logistics companies with primary focus on the orchestration of global supply chain networks that integrate different production enterprises and logistics providers [8]. All the emphasis is on the use of digital technology to transform supply chain (SC) operating models [6], identifying new ways to service the customers, places considerable emphasis on the ability of the individual, the organisation and the company to learn and to continue to learn to keep pace with the development.

Taking a second look at the DHL trend radar, the human side of supply chain management is missing. Likewise, literature and cases on SCM 4.0, [1], [16], [2] have a fascination for the technology development, using AI, IoT, Robots of different kinds etc. to optimize the flow of goods and the speed of information and decision making in supply chain. However, learning is also instrumental in driving efficiencies in supply chain.

Until recently the "soft" side of the supply chain, the managerial and behavioural, management methods, power and leadership structure, culture and attitude have been deprioritized for the fascination of technology and structures i.e. an engineering approach. In a survey in Danish industry [17], one of the significant barriers to implementation of SCM 4.0 was that it "Requires continued education of employees" and "Lack of employee readiness" [17, p.130]. This points at learning as a lever for supply chain organizations to be ready for implementation of SCM 4.0 technologies.

The American philosopher, educator and psychologist John Dewey $(1859$ - 1952) develops the theory of: "Learning by doing" [18, p.57]. Dewey is inspired by pragmatism and how psychology could be used in practice. For Dewey, training is a prerequisite for development [20], and learning processes must have a goal, a higher ethical societal 
objective. Dewey was critical of learning from a spectator perspective, to learn a person needs to be engaged - you do not become a good football player by watching from the sideline.

For Dewey, learning was "about becoming and growing as a human being, as culture and as a society." [20, p. 85]. Dewey focus on the fact that experience and education as a method are the starting point for realization and thus learning. A central concept for Dewey is "inquiry" [18]. According to Dewey, we must understand the concept of inquiry broadly, as study or experimental actions [18]. We are constantly in situations where we need "to conduct further studies and experiments" [18, p. 56]. Inquiry means that we make assumptions that we subsequently test, clarify and reformulate. Dewey's learning concept is based on learning being created in practice, but learning does not come automatically from experience, but it is necessary to combine activity and reflection to achieve learning [19]. Dewey focused on learning happening in social contexts, for example an organization as a "learning field", through the interaction in a workplace [18]. Learning can be done in situations of solving concrete problems, which leads to "learning-by-doing".

Another contribution to learning theory is the American psychologist Donald A Schön (1930-1997), who has conducted studies on how qualified employees think and act in practice. Central to Schön is the link between "thinking, reflection, action and learning" [22, p. 254]. Schön defines two key concepts - knowledge-in-action and reflection-in-action. Knowledge-in-action is found in what Schön calls intelligent actions, e.g. in riding a bike. Knowledge is in the action and is revealed through the action [22]. We are often unable to explain our action with words, we just do it. Knowledge-in-action usually takes us through everyday life. However, when a wellknown action leads to an unexpected result. An error does not resolve itself by the usual method, we are surprised about the outcome of an event [22]. There's something that doesn't happen as expected. This is where Schön introduce the second central concept of reflection-in-action.

Where knowledge-in-action is silent, spontaneous, carried out unconsciously and works as long as the action gives the intended result and the situation falls within what has been learned as being normal. Reflection-in-action is going on while acting [22]. Even our routine tasks can lead to surprise and thus to reflection-in-action. We reflect on the unexpected with questions like, "What is this?", "How have I really thought about it?" [22, p. 259]. Reflection-in-action has the important feature, to be critical of knowledge-in-action and challenge the built-in thinking. Reflection allows you to perform test actions and experiment while the action happens. New actions are being tested for new and better practices and thus leading to knowledge-in-actions [22]. When there are situations in practice that do not suit the learned (knowledge-in-action) then through reflection-in-action the individual has the opportunity to form new knowledge.

\section{Methodological considerations}

With reference to the different definitions of supply chain management [9], [11], [12], [23], SCM is cross functional and cross disciplinary of nature. SCM research have for many years been influenced by an engineering and economic approach. However, [24] calls for a pragmatic approach vs the traditional positivist approach to supply chain research and knowledge creation. In supply chain research there seems to be a primary use of quantitative methods [25]. Given that supply chain management is a complex, 
cross disciplinary research area [26] the use of qualitative data is important for uncovering the people (social) related elements of a supply chain.

The approach of abduction stems from pragmatism [26]. The father of pragmatism Charles Sanders Peirce (1839-1914) [21], pointed out that we create new knowledge "when our existing knowledge and habits prove insufficient to explain and understand a new experience" [21, p. 175]. Pragmatism is also connected to John Dewey (1859-1952), the founder of "learning by doing". As a pragmatist, Dewey was concerned with "solving problems in current societal practices". [20, p. 77].

This paper will build on the call for applying the pragmatic explorative approach abduction [24]. During the analysis we will explore the empirical data - let the empirical findings talk - and based on the patterns we see; new findings will surface. Data for the paper is secondary data, and not directly generated for the paper. However, questions investigated and findings support the topic of this research. Case data is generated through two interventions with two different groups of supply chain leaders.

Case A generate data through a three-hour workshop with a group of senior supply chain leaders, having focus on opportunities to optimize the end to end supply chain by application of SCM 4.0 technologies. The participants are all at VP level, factory directors, head of S\&OP etc. the workshop started with a recap of what constitutes a supply chain, creating a common understanding of the theory foundation for supply chain management, and SCM 4.0. Based on this, basic learning theory was introduced, and through interactive $\mathrm{Q} / \mathrm{A}$ sessions learning was related to the actual daily day of the participants, to provoke reflections on how the participants lead and learn from what they do in practice. Data was recorded as notes from the discussions, flip overs from group work containing the participants reflections on training vs learning and where they could see opportunities to do more in the current supply chain, by focusing on learning and not only training, as levers for the digital transformation of the supply chain.

Case B investigates the transformation to SCM 4.0 in six SME (Small-Medium size Enterprises) companies, seen from the perspective of the senior leaders - COO / CEO level. Data was generated through a two-hour focus group interview centred around how the SME organisations implement new SCM4.0 technology and investigating if there are traces of learning in the way of working and to what extend learning works as a lever for the SCM 4.0 implementation. Data is generated based on researcher notes and a recording of the focus group interview. The recording was not transcribed, only used as support in cases of doubt on the actual dialogues and points at the meeting. The participants have roles spanning from Owner, Board member, $\mathrm{CEO} / \mathrm{COO}$, head of business development. All six leaders have hands-on experience and responsibility for operations and supply chain of the companies. Two major stories are highlighted in the case description for illustration of the link between implementation of SCM 4.0 technology and learning in the organization.

\section{Case A - SCM 4.0 transformation in a large food supply chain}

This case is about a large company in the food industry with a global supply chain, having operations in more than 100 countries, and approximately 20.000 employees globally.

Through the workshop with the senior supply chain leaders they were challenged on how they learn, how their organization learn and train. From this, small stories were found that illustrates how the senior managers work with the transformation of the supply chain to a SCM 4.0. Strategically the company has focus on innovation of new products 
with a purpose of doing good for the public health. The leadership of the supply chain has started a digitalisation transformation to SCM 4.0.

Operating in the food industry the company must comply with a strict set of rules and regulations, on health and safety. To make sure to comply with the regulations, the company have fixed training schedules for specific functions and roles in the organization. In addition to the training schedules, a cross the supply chain organization they excel in traditional lean tools and ways of working, $5^{*}$ why, fish bone diagram for problem solving etc.

The reflection from the senior managers on the current practise is that there they do not share their own practise or have formalised reflection on practise, even in the leadership team forum. Focus for the training and follow up activities are all related to operations issues and performance follow up. The leadership team explains that it is difficult to address ways of working and have time to reflect on practice as this behaviour is not rooted in the leadership practise. One of the statements from the workshop was "why don't we ever ask why? - when the performance is green?". The story behind the question is that the supply chain leaders are highly focused on the performance KPIs, where expected performance is not met (red KPI). However, in the actual case of green performance, the leaders do not create space for reflection on what is working really well in the supply chain, and take the learnings from this into other processes and functions.

The SCM leadership team also discussed what would be the difficulties of implementing new SCM 4.0 technology in the supply chain, and the current practise of training and learning. As part of the digitalization efforts the company have analysed strength and weaknesses regarding implementation of specific digital technologies like BI (Business Intelligence) for improving the transparency of the supply chain performance, IoT in monitoring and tracking of products and trucks in distribution, Robotic Process Automation - RPA to automate ex. planning processes. The company already have experience with RPA in finance processes (invoice control etc.).

The company see RPA as having many more opportunities for improving supply chain processes. However, the company is facing a challenge of quality of master data. For the investigated processes in the supply chain there is a poor data discipline, resulting in employees losing trust in the data. This is a paradox; on one hand the company have a lot of supply chain data available but having a low data validity. The issues with data quality are rooted in a landscape of different not integrated systems, this challenges the organisation ability to optimize operations.

The SCM leadership team finds that the organisational ability to learn from practise and optimise processes is a key driver for being able to utilize SCM 4.0 technologies.

\section{Case B - SCM 4.0, technology implementation and learning in SME companies.}

This case investigates the transformation to SCM 4.0 in six SME companies, seen from the perspective of the senior leaders - COO / CEO level. Data is generated through a focus group interview with the six senior leaders from the SME companies. The participants have roles spanning from Owner, Board member, $\mathrm{CEO} / \mathrm{COO}$, head of business development. All six leaders have hands-on experience and responsibility for operations and supply chain of the company. The focus group participants are all part of a network group in the printing industry. The network group was established in 1987 and have therefore a long history on the technology development in the printing industry and 
also the network group have a high trust level and are able to discuss complex leadership issues. Two major stories are highlighted here for illustration of the link between implementation of SCM 4.0 technology and practise-based learning.

The focus group interview was centred around how the SME organisations implements new SCM4.0 technology and investigating if there are traces of learning in the way of working and to what extend learning works as a lever for the SCM 4.0 implementation. Through the focus group interview small stories was found that illustrates how the senior managers work with technology implementation. An example is one of the participants explaining how a new automated machine in the printing production, delivered a poor-quality output and how the leadership team and the operators structured in the search for solutions. In this chase the team sorted all errors from the machine and coded the poor-quality samples and based on this build knowledge about the process in the new automated machine that led to new solutions.

Another story from one of the participants is based in the logistics part of the printing supply chain. The company experienced that a new SCM4.0 online transport booking platform, changed the processes for the drivers and their connection to the customers. Before the new booking platform, the drivers were in direct contact with the customers. However, the new platform was automating the information flow between customers and drivers and the company experienced that errors e.g. missing information in labels, packaging not suitable for transport etc. that previously was handled by the drivers, now, because of the changes in process based on the new booking platform with no interaction between customer and driver, was suddenly issues that could jeopardize the shipping of the products.

\section{Analysis and discussion}

Based on the two cases the analysis and discussion will explore how practise-based learning can support the transformation of a supply chain into a version 4.0 digital supply chain. We are curious to see if we can find traces of learning from practise like defined by Dewey, "learning-by-doing" and "inquiry" [19], or "reflection-in-action" to "learning-in-action" [22] as the foundation for the supply chain organisation to cope with the transformation to a digital supply chain (SCM 4.0).

In case A, the supply chain leadership team, discussed the different ways of training in the supply chain, and found that they have many different training courses and also, they have formalized apprenticeship forms of on-the-job training. All of the trainings were found to be rooted in the ability to master a tool e.g. a lean process tool like $5^{*}$ why, fish bone diagram for problem solving etc. this way of training looks at first like Dewey's "learning by doing". However, an important element of the learning practise from Dewey is the "inquiry". This is where the individual asks the - why does this happen as it is?. Listening to the SCM leaders in case A, this inquiry on the process does not happen systematically. This also points at the learning based on Schön [22], the reflection is not happening, this means that the organization does not systematically create new knowledge based on the practise.

Challenging the leadership team in their own practise the reflection is that they do not have a structured practise of reflection on practise, like described by Schön [22] and the leadership team do not create new knowledge from their practice. The missing structed learning approach is also seen in the issues of supply chain master data quality, where lack of reflection on practise is leading to missing actions on improving the master 
data quality, and this is critical as high master data quality is a precondition for digitalisation of the supply chain and using the SCM 4.0 technology of RPA to optimize supply chain business processes.

In case B we found two stories of implementation of new technology in the SME supply chain. The first case was implementation of a new automated production process. Here we found that the leadership team used a highly structured approached to the challenge of getting the new automated process to work. This support the learning process described by Schön [22], reflection-in-action leading to knowledge-in-action. The structured approach to the automation challenge points at a leadership team involving the full supply chain in the learning process.

The other example from case B is the implementation of a new SCM 4.0 online transport booking platform. The changes to processes lead to the truck drivers need to learn a new way of working. During the implementation the reflection on the business processes and ways of working reviled that the new booking platform was not the most important issue for the drivers. The inquiry into the new processes (Dewey) [19], showed that it was the quality of packaging provided by the customers that was the most important issue to solve to secure the success of the new SCM 4.0 online transport booking platform.

\section{Conclusion}

The research question guiding the study is: to what extent can practise-based learning be a lever for adapting SCM 4.0? To answer the question, we have built on the call for an abductive approach [24] to knowledge creation by outlining the two cases of supply chain transformation to SCM 4.0, searching for stories that points at the use of practisebased learning.

Taking a people focus on the development of SCM 4.0 we found that it has a historic link to the industrialization in the beginning of the twentieth century. Until recently the "soft" side of the supply chain, have been deprioritized for the fascination of technology and structures. This is giving a challenge when transforming from SCM 2.0 to SCM 4.0. The current supply chain models do not capture the complex leadership task of a supply chain 4.0 [5]. This is also indicated by a supply chain survey in Danish industry [14] which points at learning as a lever for supply chain organizations to be ready for implementation of SCM 4.0 technologies.

The two cases both show traces of practise based learning, learning by doing, inquiry, and reflection in action to knowledge in action. Also, the cases show that learning can be a lever for adapting SCM 4.0 technologies in a traditional supply chain. Another finding from the cases is that the organisational ability to learn from practise and optimise processes is important for being able to utilize SCM 4.0 technologies. However, we find that this is not systematically happening. There seems to be little awareness on learning in practise. The "muscle" of reflection and inquiry is untrained at best it is mechanical - " $5 \mathrm{~S}$ " exercises and solving of operational issues.

In supply chain, learning is often translated to training in many different shapes and forms. To help the transformation of supply chain practise from SCM 2.0 to SCM 4.0, companies need to develop a conscious and systematic learning practise. A few leadership practise steps in this direction would be, based on Dewey [19], [20], to create room for experiments and reflections on current practise, to cultivate psychological safety in the organizations [27], and to develop a practice of systematically giving 
feedback on behaviour and performance, this would be baby steps towards building a supply chain learning culture.

\section{References}

[1] L.G. Frank, L.S.Dalenogare, N.F. Ayala, Industry 4.0 technologies: Implementation patterns in manufacturing companies, International Journal of Production Economics, 2019, Vol. 210, pp. 15-26, https://doi.org/10.1016/j.ijpe.2019.01.004.

[2] S. Vaidya, P. Ambad, S. Bhosle, Industry 4.0 - A Glimpse, Procedia Manufacturing, 2018, Vol. 20, pp. 233-238, ISSN 2351-9789, https://doi.org/10.1016/j.promfg.2018.02.034.

[3] A. Calatayud, J. Mangan and M. Christopher, The self-thinking supply chain, Supply Chain Management, 2019, Vol. 24, No. 1, pp. 22-38. https://doi.org/10.1108/SCM-03-2018-0136.

[4] R.J. Calantonea, L.S.T. Cavusgila, Y. Zhao, Learning orientation, firm innovation capability, and firm performance, Industrial Marketing Management, 2002, Vol. 31, pp. 515-524.

[5] J. Bessant, R. Kaplinsky and L. Lamming, Putting supply chain learning into practice, International Journal of Operations \& Production Management, 2003, Vol. 23 Issue: 2, pp. 167-184 https://doi.org/10.1108/01443570310458438

[6] G.J. Hahn, Industry 4.0: a supply chain innovation perspective, International Journal of Production Research, 2019, 58:5, pp. 1425-1441, DOI: 10.1080/00207543.2019.1641642.

[7] H. Kagermann, , W. Wahlster, and J. Helbig. Recommendations for Implementing the Strategic Initiative Industrie 4.0: Final Report of the Industrie 4.0 Working Group. Acatech-National Academy of Science and Engineering, Germany. 2013. Retrived from, May 2019, https://www.din.de/blob/76902/e8cac883f42bf28536e7e8165993f1fd/recommendations-forimplementing-industry-4-0-data.pdf

[8] D. Markis, Z.N.L. Hansen, O. Khan, Adapting to Supply Chain 4.0: An explorative study of multinational companies, Supply Chain Forum: An International Journal, 2019, 20:2, pp. 116-131.

[9] R.K. Oliver and M.D. Webber, 1982, Supply chain management: Logistics catches up with strategy, In: M. Christopher, (ed.), Logistics: The Strategic Issues, Chapman\&Hall, London, 1992.

[10] M. Christopher, Logistics and Supply chain management: Strategies for Reducing cost and improve performance. Prentice Hall, London,1998.

[11] D. M. Lambert, M. C. Cooper, J. D. Pagh, Supply chain management: Implementation issues and research opportunities. International Journal of Logistics Management, 1998, 9(2), 1. doi:http://dx.doi.org.ez.statsbiblioteket.dk:2048/10.1108/09574099810805807

[12] J.S. Arlbjørn, H. de Haas, O.S. Mikkelsen and F.Zachariassen, Supply Chain Management: Sources for Competitive Advantage, 1st ed. Academica, Aarhus, 2010.

[13] N.P. Archer, P. Hong and J. Jeong, Supply Chain Management Practices of SMEs: From a Business Growth Perspective, Journal of Enterprise Information Management. 2006, 19.3, 292-302.

[14] J.S. Arlbjørn, O.S. Mikkelsen and C. Rajkumar, Supply Chain Management : Sources for Competitive Advantages. 2. edition. 1. print. Hans Reitzel, Kobenhaven, 2018.

[15] DHL Logistics trend radar, 2019, https://www.logistics.dhl/global-en/home/insights-andinnovation/thought-leadership/trend-reports/logistics-trend-radar.html Accessed may 2019

[16] G. Benitez, M. Ferreira Lima, L. Lerman and A. Frank, Understanding Industry 4.0: Definitions and insights from a cognitive map analysis. Brazilian Journal of Operations \& Production Management, 2019, Vol. 16(2), 192-200. https://doi.org/10.14488/BJOPM.2019.v16.n2.a3

[17] Arlbjørn, J.S. (2017) Practitioners Perspectives on Contemporary Supply Chain Management: Issues, The Danish Supply Chain Panel 2012-2016. Odense: University Press of Southern Denmark

[18] Nielsen, K. \& Tanggard, L., (2018). Padagogisk Psykologi - en grundbog. 2. Udgave. Samfundslitteratur.

[19] Glassman, M. (2001). Dewey and Vygotsky: Society, Experience, and Inquiry in Educational Practice. Educational Researcher, 30(4), 3-14. https://doi.org/10.3102/0013189X030004003

[20] Elkjær, B. (2005), når laering går på arbejde - et pragmatisk blik på laering i arbejdslivet, 1. udg., Samfundslitteratur

[21] Egholm, L. (2014). Videnskabsteori, perspektiver på organisationer og samfund. 1.udg,. 3.opl., Hans Reitzels Forlag

[22] Schön, D. (2000), Udvikling af ekspertise gennem refleksion-i-handling, i Illeris, K., (red.) Tekster om Laring 1. udg. S.254-269, Roskilde Universitetsforlag.

[23] Christopher, M., 2016. Logistics \& Supply Chain Management. Pearson UK 
[24] Kovács, G., \& Spens, K. M. (2005). Abductive reasoning in logistics research. International Journal of $\begin{array}{lllll}\text { Physical Distribution \& Logistics } \quad \text { Management, } & 35(2), & 132-144\end{array}$ doi:http://dx.doi.org.ez.statsbiblioteket.dk:2048/10.1108/09600030510590318

[25] Golicic, S. L., \& Davis, D. F. (2012). Implementing mixed methods research in supply chain management. International Journal of Physical Distribution \& Logistics Management, 42(8), 726-741 doi: http://dx.doi.org.ez.statsbiblioteket.dk:2048/10.1108/09600031211269721

[26] Boyer, K.K. and Swink, M.L. (2008), Empirical Elephants-Why Multiple Methods are Essential to Quality Research in Operations and Supply Chain Management. Journal of Operations Management, 26 : 338-344. doi:10.1016/j.jom.2008.03.002

[27] Brotheridge, C., \& Lee, R. (Eds.). (2008). The emotions of managing: an introduction to the special issue. In Emotions of managing: The emotions of managing. Journal of Managerial Psychology Vol. 23 No. 2, pp. 108-117. DOI 10.1108/02683940810850763 